Check for updates

Cite this: RSC Adv., 2018, 8, 40712

Received 26th September 2018 Accepted 26th November 2018

DOI: 10.1039/c8ra07995a

rsc.li/rsc-advances

\title{
Synthesis and characterization of nickel-doped ceria nanoparticles with improved surface reducibility $\dagger$
}

\author{
Wassila Derafa, ${ }^{\text {ab }}$ Fotios Paloukis, ${ }^{a}$ Basma Mewafy, ${ }^{a}$ Walid Baaziz, ${ }^{c}$ Ovidiu Ersen, (D) \\ Corinne Petit, ${ }^{a}$ Gwenaël Corbel (iD d and Spyridon Zafeiratos (iD *a
}

\begin{abstract}
Nickel-doped ceria nanoparticles $\left(\mathrm{Ni}_{0.1} \mathrm{Ce}_{0.9} \mathrm{O}_{2-x} \mathrm{NPs}\right)$ were fabricated from Schiff-base complexes and characterized by various microscopic and spectroscopic methods. Clear evidence is provided for incorporation of nickel ions in the ceria lattice in the form of $\mathrm{Ni}^{3+}$ species which is considered as the hole trapped state of $\mathrm{Ni}^{2+}$. The $\mathrm{Ni}_{0.1} \mathrm{Ce}_{0.9} \mathrm{O}_{2-x} \mathrm{NPs}$ exhibit enhanced reducibility in $\mathrm{H}_{2}$ as compared to conventional ceria-supported $\mathrm{Ni}$ particles, while in $\mathrm{O}_{2}$ the dopant nickel cations are oxidized at higher valence than the supported ones.
\end{abstract}

\section{Introduction}

Cerium(Iv) oxide, also known as ceria $\left(\mathrm{CeO}_{2}\right)$, is largely exploited in catalysis and electrocatalysis, ${ }^{\mathbf{1}}$ such as for example, as a constituent of three-way automotive catalysts. ${ }^{2}$ The unique catalytic properties of ceria have been connected to the facile and reversible exchange between $\mathrm{Ce}^{4+}$ and $\mathrm{Ce}^{3+}$ oxidation states which allows fast uptake and release of oxygen under oxidizing and reducing conditions, respectively. Although oxidation of $\mathrm{Ce}^{3+}$ ions is kinetically fast, the reduction of $\mathrm{Ce}^{4+}$ is generally sluggish, therefore great effort has been devoted to promote ceria reducibility ${ }^{3}$ either by modifying the size and the morphology of the crystals or by partial substitution of cerium by metal ions. ${ }^{4,5}$ The latter has been also exploited as a strategy to produce catalysts containing metal ions atomically dispersed on the oxide support, usually referred to as single-atom catalysts. ${ }^{6,7}$ A prerequisite for the synthesis of metal-substituted ceria particles is the formation of a homogenous solid solution between the metal and ceria. Conventional catalyst synthesis methods, e.g. co-precipitation, are not capable of that and typically lead to the formation of segregated metal/ceria agglomerates. ${ }^{8}$ Therefore, realizing the

anstitut de Chimie et Procédés pour l'Energie, l'Environnement et la Santé (ICPEES), ECPM, UMR 7515 CNRS, Université de Strasbourg, 25 rue Becquerel, 67087 Strasbourg Cedex 02, France. E-mail: spiros.zafeiratos@unistra.fr

${ }^{b}$ Chemistry Department, College of Science, Jouf University, P. O. Box: 2014, Sakaka, Saudi Arabia

'Institut de Physique et Chimie des Matériaux de Strasbourg (IPCMS), UMR 7504 du CNRS, Université de Strasbourg, 23 rue du Loess, 67037 Strasbourg Cedex 08, France 'Institut des Molécules et Matériaux du Mans, IMMM-UMR 6283 CNRS, Le Mans Université, Avenue Olivier Messiaen, 72085 Le Mans Cedex 9, France

$\dagger$ Electronic supplementary information (ESI) available: Experimental details of synthesis and characterization, STEM images of NiCe NPs, in situ XRD analysis during redox cycles. See DOI: 10.1039/c8ra07995a homogeneous dispersion of metal into the ceria lattice is a critical challenge in the effort to synthesize novel singleatom catalysts and there are only few available methods for that. Recently W. L. Wang et al., ${ }^{9}$ proposed a synthesis route that involves a solution of the two metal salts which react in a continuous reactor in the presence of supercritical water $\left(374{ }^{\circ} \mathrm{C}\right.$ and $\left.23 \mathrm{MPa}\right)$. Alternatively, S. McIntosh and coworkers, demonstrated that $\mathrm{Cu}$-doped ceria nanoparticles can be synthesized at room temperature in aqueous solution using a modified base precipitation method. ${ }^{10}$ These methods do not involve organic compounds and so, does not require a cleaning step after preparation. On the downside, the absence of an organic protective layer constitutes the particles potentially vulnerable to aggregation and agglomeration. In an alternative synthesis method put forward by Elias et al. ${ }^{\mathbf{1 1}}$ a solution-based pyrolysis route is followed to produce phase pure, monodisperse $\mathrm{M}_{0.1} \mathrm{Ce}_{0.9} \mathrm{O}_{2-x}(\mathrm{M}: \mathrm{Ni}, \mathrm{Co}, \mathrm{Au})$ nanoparticles. To ensure close association of cerium and transition metal ions during their nucleation and growth heterobimetallic Schiff base complexes were used as inorganic precursors. By this method the nanoparticles are surrounded by an oleylamine protective layer, which allows obtaining narrow size distributions of relatively small particles ( $c a .3$ $\mathrm{nm}$ ). However, the synthesis is relatively complex since it requires 3 consecutive steps.

In this work we modulate/simplified the previously proposed method $^{\mathbf{1 1}}$ to prepare nickel-doped ceria NPs from Schiff base metal complexes obtained in one step, without pre-synthesis of the salpn ( $N, N^{\prime}$-bis(salicylidene)-1,3-diaminopropane) ligand molecule. The structure and composition of the produced NPs were verified by various methods, including XPS, HR-TEM, Raman and $\mathrm{XRD}$, while their surface reducibility is compared to conventional supported $\mathrm{Ni} / \mathrm{CeO}_{2}$ using in situ structural and surface sensitive techniques. 


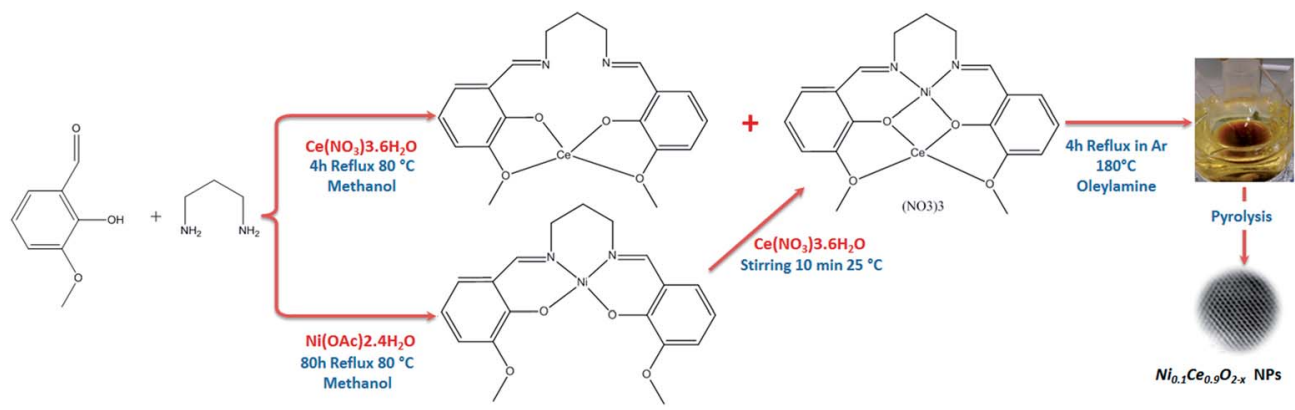

Scheme 1 Schematic illustration of the preparation of the $\mathrm{Ni}_{0.1} \mathrm{Ce}_{0.9} \mathrm{O}_{2-x}$ nanoparticles.

\section{Materials and methods}

\section{Synthesis of $\mathrm{Ni}_{0.1} \mathrm{Ce}_{0.9} \mathrm{O}_{2-x}$ nanoparticles}

The $\mathrm{Ni}_{0.1} \mathrm{Ce}_{0.9} \mathrm{O}_{2-x}$ nanoparticles (hereafter abbreviated as NiCe NPs) were synthesized by mixing the heterobimetallic Schiff base complexes precursors in oleylamine and reflux the mixture at $180{ }^{\circ} \mathrm{C}$ under $\mathrm{Ar}$ (see Scheme 1). The Schiff base complexes were prepared directly, without using a Schiff base ligand as in ref. 11. For characterization, the NiCe NPs were dispersed in hexane solution and dropped casted on various inert supports (polycrystalline gold foil, silicon wafer and fused quartz glass) and the solvent was allowed to evaporate at room temperature, leaving a layer of nanoparticles grafted on the support. A reference $10 \% \mathrm{Ni} / \mathrm{CeO}_{2}$ sample (hereafter $\mathrm{Ni} / \mathrm{CeO}_{2}$ ) was prepared by the co-precipitation synthesis route. Detailed description of the synthesis and the characterization methods is included in ESI $1 . \dagger$

\section{Characterization methods}

The X-ray photoelectron spectroscopy (XPS) analysis chamber is equipped with VSW Class WA hemispherical electron analyzer (150 $\mathrm{mm}$ radius) and a monochromatic $\mathrm{Al} \mathrm{K} \alpha \mathrm{X}$-ray source $(1486.6 \mathrm{eV})$. Oxidation/reduction treatments were carried out in a flow-through variable-pressure reactor attached to the UHV setup (0.6 L volume). Each oxidation/reduction step lasted $30 \mathrm{~min}$ at constant temperature and gas pressure. The pressure of the gas $\left(\mathrm{H}_{2}\right.$ or $\left.\mathrm{O}_{2}\right)$ treatment was 7 mbar. Subsequently to the gas treatment, the sample was cooled to room temperature in gas and the reactor was evacuated to $5 \times 10^{-8}$ mbar. Then the sample was transferred in vacuum into the analysis chamber for XPS characterization.

The XRD spectra were recorded at $25^{\circ} \mathrm{C}$ intervals between 25 and $400{ }^{\circ} \mathrm{C}$ (heating rate of $10{ }^{\circ} \mathrm{C} \mathrm{min}^{-1}$, temperature stabilization for $20 \mathrm{~min}$, cooling rate of $60^{\circ} \mathrm{C} \mathrm{min}^{-1}$ ) by using a XRK 900 Anton Paar reactor chamber attached to a PANalytical $\theta / \theta$ Bragg-Brentano Empyrean diffractometer $\left(\mathrm{CuK} \alpha_{1+2}\right.$ radiations $)$ equipped with the PIXcel ${ }^{1 \mathrm{D}}$ detector. The sample was deposited on the sieve (pore size $\varnothing 0.2 \mathrm{~mm}$ ) of the open sample holder cup, both made of glass ceramic Macor, thus allowing gas to flow through and eventually reacting with the sample. For $\mathrm{CeO}_{2} /$ $\mathrm{NiO}(10 \mathrm{~mol} \%)$ powder sample, the diffractogram was collected at each temperature in the $\left[20-130^{\circ}\right]$ scattering angle range with a $0.0131^{\circ}$ step for a total acquisition time of $220 \mathrm{~min}$. For $\mathrm{Ni}_{0.1} \mathrm{Ce}_{0.9} \mathrm{O}_{2-x}$ drop casted sample, the diffractogram was collected at each temperature in the $\left[20-65^{\circ}\right]$ scattering angle range with a $0.0131^{\circ}$ step for a total acquisition time of $155 \mathrm{~min}$. The program FullProf ${ }^{12}$ was used for Le Bail refinements. The size of the coherent diffusion domains, which are frequently assigned to the average particle size, was estimated by measuring the full-width at the half maximum (FWHM) of the Bragg peaks, taking into account the instrumental contribution. Typically the error in such estimation is considered around $10 \%$.

Raman spectra were acquired using a micro-Raman spectrometer (Horiba LabRam), with excitation wavelength of $532 \mathrm{~nm}$. A $100 \times$ objective was used to focus the excitation laser to an approximately $1 \mu \mathrm{m}$ spot with a laser power of less than 1 $\mathrm{mW}$ to avoid heating and damage of the sample.

The surface morphology was inspected by SEM using a Zeiss GeminiSEM 500 microscope. Energy-dispersive X-ray spectroscopy (EDXS) mapping was combined with the SEM images to resolve the different elements on the surface of the electrodes. The TEM analysis of $\mathrm{Ni}_{0.1} \mathrm{Ce}_{0.9} \mathrm{O}_{2-x}$ was carried out in scanning mode (STEM) using bright field and annular dark field detectors on a JEOL $2100 \mathrm{~F}$ working at $200 \mathrm{kV}$, equipped with a probe aberration corrector. The sample powder was dispersed in a beaker containing ethanol solution and sonicated for 5 minutes inside an ultrasound bath. Then, a dropper (Pasteur pipette) was used to deposit one drop of the as prepared solution on a commercial copper grid covered with a holey carbon membrane destined to the TEM observation.

\section{Results and discussion}

\section{Characterization of $\mathrm{Ni}_{0.1} \mathrm{Ce}_{0.9} \mathrm{O}_{2-x}$ nanoparticles and films}

The X-ray diffraction (XRD) patterns of NiCe NPs before and after calcination are shown in Fig. 1a. Both patterns are characteristic of fluorite-type $\mathrm{CeO}_{2}$ phase without extra peaks originating from Ni-containing phase. The absence of Ni diffraction peaks indicates the successful introduction of the entire amount of $\mathrm{Ni}$ ions in the ceria lattice and the absence of segregated nickel. ${ }^{13}$ The cubic unit cell parameter is slightly increasing after calcination from 5.421(1) $\AA$ to 5.424(1) $\AA$ in good agreement with the parameter determined by Elias et al. for ceria NPs $\left(a_{\text {Ceria }} \approx 5.42 \AA\right) .{ }^{11}$ The unit cell parameter for the 

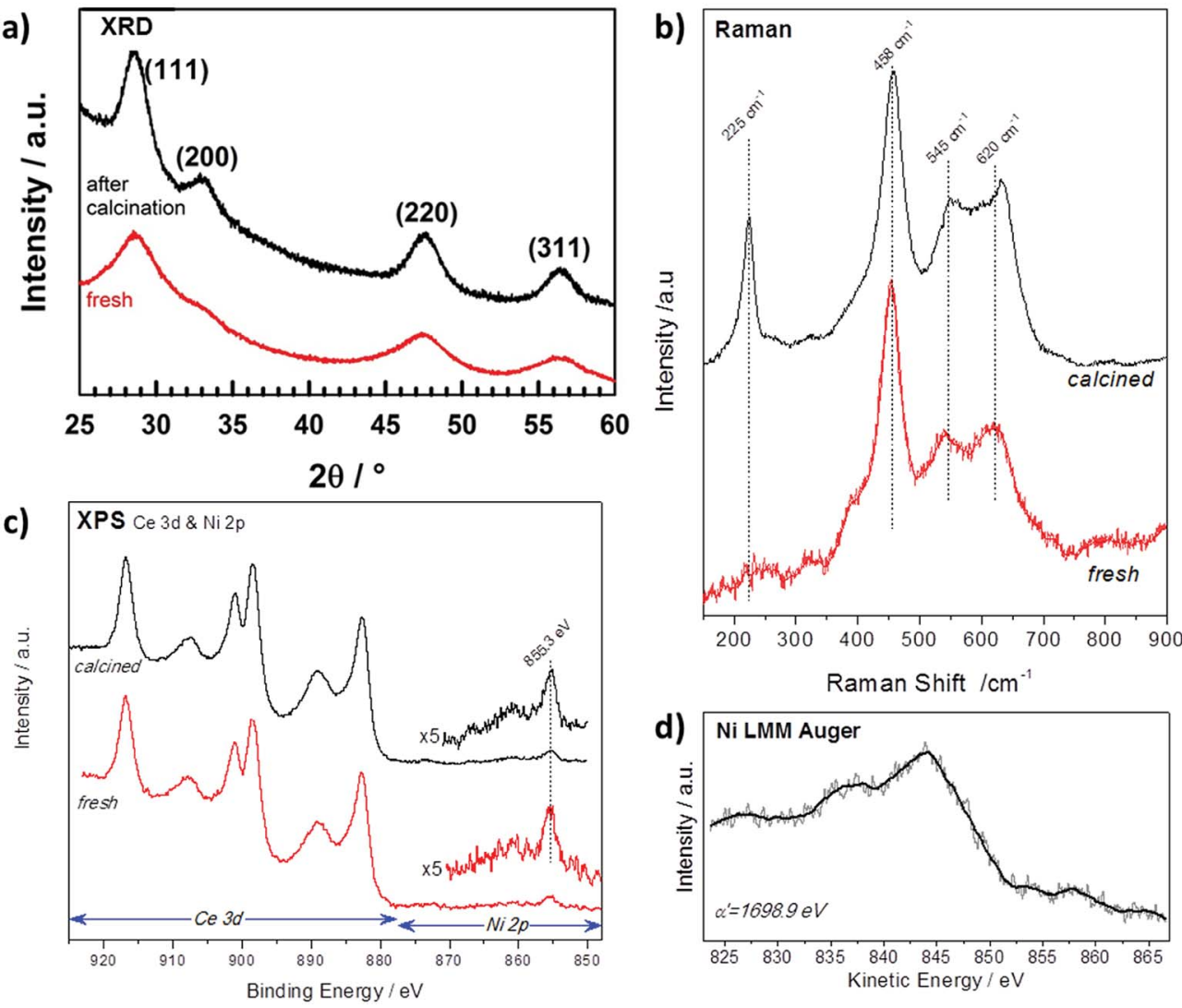

Fig. 1 (a) XRD patterns (b) Raman spectra and (c) XPS spectra (d) Auger spectrum of $\mathrm{Ni}_{0.1} \mathrm{Ce}_{0.9} \mathrm{O}_{2-x}$ particles as synthesized (red) and after calcination at $400{ }^{\circ} \mathrm{C}$ in $\mathrm{O}_{2}$ (black).

NiCe NPs is larger than the one typically reported for undoped bulk $\mathrm{CeO}_{2}$ grains $(5.411 \AA) \cdot{ }^{14}$ At first sight this may appear to oppose the fact that nickel ion is smaller in size than $\mathrm{Ce}^{4+},{ }^{15}$ however the lattice expansion can be explained by the creation of extrinsic oxygen vacancies through the aliovalent substitution of $\mathrm{Ce}^{4+}$ with $\mathrm{Ni}^{n+}$.

Raman spectroscopy is sensitive to the modification of the local structure of the ceria crystal and particularly to lattice defects. ${ }^{16}$ Fig. $1 \mathrm{~b}$ shows the baseline corrected Raman spectra of fresh and calcined NiCe NPs. The main Raman band at $458 \mathrm{~cm}^{-1}$ corresponds to the triply degenerate $F_{2 g}$ mode of fluorite-type ceria structure and it can be considered as the symmetric stretching mode of oxygen atoms around cerium ions. ${ }^{17}$ Two addition features are observed at about 545 and $620 \mathrm{~cm}^{-1}$ which according to previous studies are induced by defects in the ceria structure. ${ }^{16,18}$ The lower-wavenumber band at $545 \mathrm{~cm}^{-1}$ is attributed to defect sites that include an $\mathrm{O}^{2-}$ vacancy (extrinsic vacancy), while the higher-wavenumber band at $620 \mathrm{~cm}^{-1}$ is induced by the presence of $\mathrm{Ce}^{3+}$ or $\mathrm{Ni}^{3+}$ ions. ${ }^{16,18-20}$ The peak at $225 \mathrm{~cm}^{-1}$ is the transverse optical (TO) phonon mode, which, it becomes Raman active due to the disorder induced by doping in $\mathrm{CeO}_{2} \cdot{ }^{20}$ Comparison of the Raman spectra before and after calcination in Fig. 1b shows that fresh NiCe particles contain a great number of defect sites which, to a large extent, remain also after calcination at $400{ }^{\circ} \mathrm{C}$. Since the amount of extrinsic oxygen vacancies is directly related to the oxidation state of nickel ions, this indicates the stability of nickel oxidation state during calcination.

XPS can be used to confirm the oxidation state of Ce and Ni ions as well as to their surface arrangement. ${ }^{21}$ In Fig. 1c are presented the Ce $3 \mathrm{~d}$ and $\mathrm{Ni} 2 \mathrm{p}$ spectra before and after calcination of NiCe NPs. The Ce 3d photoelectron peak contains several multiple splitting features including the intense peak at $916.8 \mathrm{eV}$ which is characteristic for $\mathrm{Ce}^{4+}$ ions. ${ }^{21} \mathrm{The} \mathrm{Ni} 2 \mathrm{p}_{3 / 2}$ line is composed by a main peak at $855.3 \pm 0.1 \mathrm{eV}$ and a satellite feature at higher binding energies with relative intensity about $25 \pm 5 \%$ of the main Ni $2 \mathrm{p}_{3 / 2}$ peak. The binding energy (BE) position and the peak shape do not correspond to nickel oxides or hydroxides reported in relevant literature. ${ }^{22-25}$ Similarly, the Ni LMM Auger peak shape and the so called modified Auger parameter $\left(\alpha^{\prime}\right)$ at $1698.9 \mathrm{eV}$ shown in Fig. 1d, differ from previously published results of oxidized nickel compounds. ${ }^{24}$

These findings suggest that the chemical environment around Ni cations varies from the known bulk nickel oxides (e.g. $\mathrm{NiO}$ ). On the other hand, previous studies of $\mathrm{Ni}^{3+}$ species formed after potassium interaction with $\mathrm{NiO}^{26,27}$ exhibit similar $\mathrm{Ni} 2 \mathrm{p}_{3 / 2}$ peak characteristics with the one found here, which is strong evidence that in the case of NiCe NPs, nickel is mainly in the $\mathrm{Ni}^{3+}$ state. More conclusive results about the oxidation state of nickel will be provided after comparison with supported nickel oxide particles in the next section. The $\mathrm{Ni}$ : Ce atomic stoichiometry calculated by XPS is found $12: 88 \pm 2 \%$, close to 
the expected stoichiometry of $\mathrm{Ni}_{0.1} \mathrm{Ce}_{0.9} \mathrm{O}_{2-x}$ particles $(10: 90)$. This stoichiometry remains constant after calcination which indicates the stability of the NPs during this process and excludes surface segregation phenomena. Overall XRD, Raman and XPS analysis of the NiCe NPs provides solid evidence for the formation of $\mathrm{Ni}$ doped-ceria particles with the expected stoichiometry and high stability to the calcination procedure.

The SEM micrograph of the NiCe NPs applied by drop casting on a $\mathrm{SiO}_{2} / \mathrm{Si}$ substrate is shown in Fig. 2a. The texture of the fresh film is not homogenous and consists of flat areas interrupted by parts where the texture is porous. After calcination at $400{ }^{\circ} \mathrm{C}$ and removal of the capping oleylamine layer, the NPs have the tendency to agglomerate and form a flat and homogenous film on both $\mathrm{SiO}_{2} / \mathrm{Si}$ and $\mathrm{Au}$ foil substrates as
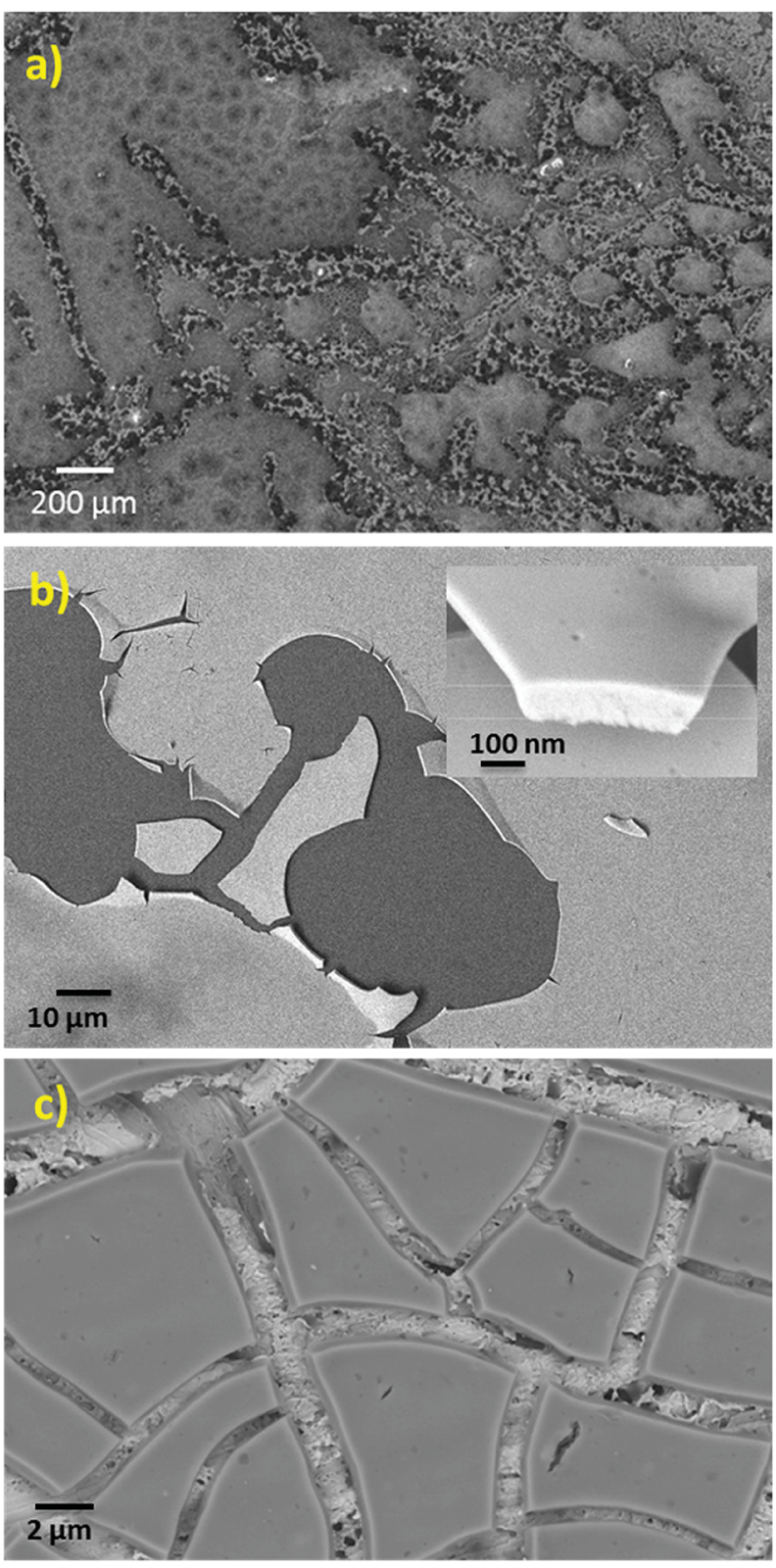

Fig. 2 SEM images of a $\mathrm{Ni}_{0.1} \mathrm{Ce}_{0.9} \mathrm{O}_{2-x}$ layer (a) fresh after drop casting the solution on $\mathrm{S} \mathrm{SiO}_{2} / \mathrm{Si}$ wafer (b) after calcination at $400{ }^{\circ} \mathrm{C}$ on a $\mathrm{SiO}_{2} /$ Si wafer and (c) after calcination at $400^{\circ} \mathrm{C}$ on a Au polycrystalline foil. shown in Fig. 2b and c. Apparently, the flat nature of the NiCe NPs film demonstrates the tendency of the solution to wet the support and form layers instead of agglomerated particles. Based on the quantitative analysis of the SEM images using EDX the $\mathrm{Ni}$ atomic ratio was found $11.0 \pm 1.5 \%$, which is in good agreement with both XPS findings and the nominal Ni loading.

The HR-TEM images (Fig. 3a and S2 (ESI)†) after calcination shows aggregated NiCe NPs with a mean diameter of about $4 \mathrm{~nm}$, similar to previous work..$^{11}$ Typical high resolution STEM images (Fig. 3b and c) show the high crystallinity of the calcined NiCe NPs and reveal that the crystallites are formed in truncated octahedral crystal habits. The corresponding Fast Fourier Transform (FFT) patterns (Fig. 3d) suggest that the $\{111\}$ and $\{100\}$ are the mainly exposed facets of the NPs.

\section{Investigation of the redox properties of $\mathrm{Ni}_{0.1} \mathrm{Ce}_{0.9} \mathrm{O}_{2-x}$ nanoparticles}

The redox stability of NiCe NPs is investigated next, in comparison with supported $\mathrm{Ni} / \mathrm{CeO}_{2}$ of the same nominal composition. Generally in catalytic studies temperature programmed methods (TP) are employed to examine the redox properties. However such methods are not suitable for NiCe NPs since require a relatively high solid sample loading, which bypass the capacity of the synthesis method and needs scale up. Furthermore, TP methods present some drawbacks mostly related to the overlapping of the peak profiles and the difficulty to identify with certainty surface and bulk processes. Alternatively, analytical methods can be used to provide direct information about the oxidation state during, or after, redox treatments. ${ }^{28,29}$ Although this is a more elaborate approach, is preferential for the purpose of this study since it can be specific on the surface redox properties providing that surface sensitive methods are used.

In ESI $3 \uparrow$ in situ temperature controlled XRD experiments obtained during consecutive reduction and oxidation (redox) cycles of pre-calcined NiCe NPs and $\mathrm{Ni} / \mathrm{CeO}_{2}$ are compared in Fig. S3. $\dagger$ The diffraction patterns of the NiCe are similar to that of pure $\mathrm{CeO}_{2}$ cubic structure and remain almost identical in both $\mathrm{H}_{2}$ and $\mathrm{O}_{2}$ atmospheres for all annealing temperatures (Fig. $\mathrm{S} 3 \dagger$ ). Notably, there is no appearance of diffraction peaks related to $\mathrm{Ni}$ or NiO. The calculated cubic unit cell parameter of NiCe NPs remains practically constant in both atmospheres (Table 1 ). Therefore, within the XRD detection limits, the NiCe NPs are stable during the redox treatment in terms of dispersion and nature of the presented phases in good agreement with previous ex situ XRD reports. ${ }^{30}$ The average apparent size of the NiCe crystallites determined at room temperature (by refinement after removing the instrumental line broadening) was $20(2) \AA$, and 37(4) $\AA$ after calcination at $400{ }^{\circ} \mathrm{C}$ in $\mathrm{O}_{2}$ and $\mathrm{H}_{2}$, respectively, which is in good agreement with the HR-TEM results. The results show that the NPs can be reduced inducing a large amount of oxygen vacancies while keeping their structure practically stable. In contrast to NiCe NPs, in the XRD pattern of $\mathrm{Ni} / \mathrm{CeO}_{2}$ in addition to the $\mathrm{CeO}_{2}$ diffraction, Ni-related peaks are detected (Fig. $\mathrm{S} 3 \dagger$ ). In particular, the calcined $\mathrm{Ni} / \mathrm{CeO}_{2}$ contains a large (200) Bragg peak at around $43.3^{\circ}$ in $2 \theta$ assigned to NiO. When 

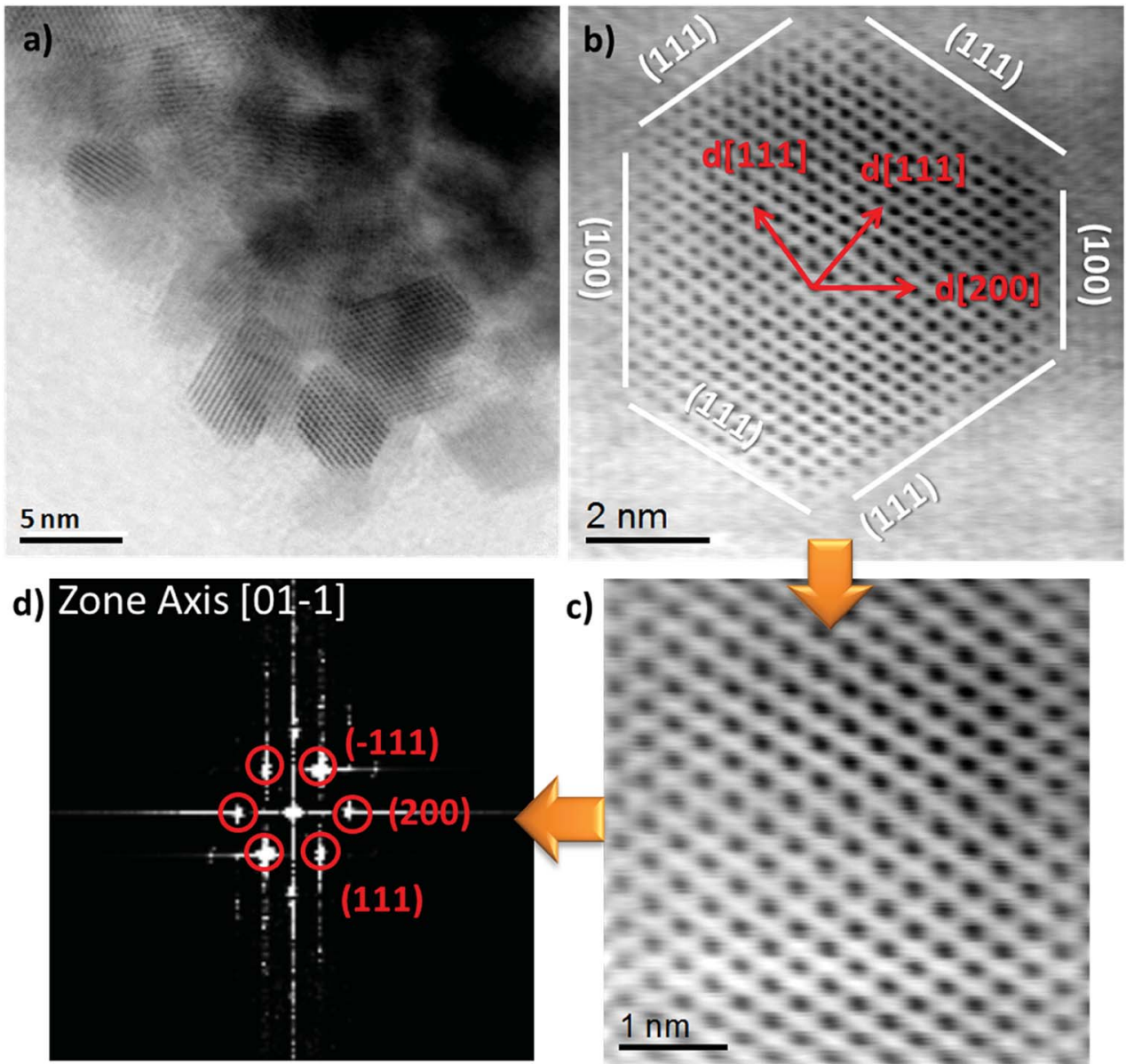

Fig. 3 High resolution bright field STEM image and the corresponding FFT diffraction pattern of $\mathrm{Ni}_{0.1} \mathrm{Ce}_{0.9} \mathrm{O}_{2-x}$ formed after calcination at $400{ }^{\circ} \mathrm{C}$.

annealed in $\mathrm{H}_{2}$, a complete reduction of $\mathrm{NiO}$ into $\mathrm{Ni}$ occurs at $300{ }^{\circ} \mathrm{C}$ (appearance of the (111) peak at around $44.5^{\circ}$ in $2 \theta$ assigned to $\mathrm{Ni}$ in Fig. $\mathrm{S} 3 \dagger$ ). In a consecutive reoxidation cycle, a large amount of metallic $\mathrm{Ni}$ remains present even after annealing in $\mathrm{O}_{2}$ at $400{ }^{\circ} \mathrm{C}$ the reoxidation is therefore partial (Fig. S3†). The diffraction peaks related to $\mathrm{CeO}_{2}$ and accordingly the cubic unit cell parameters of $\mathrm{Ni} / \mathrm{CeO}_{2}$ sample remain practically stable during both redox treatments (Table 1).

The XPS analysis performed under gas and temperature conditions similar to XRD is informative of the stability in the near surface region. The Ce $3 \mathrm{~d}$ and $\mathrm{Ni} 2 \mathrm{p}$ spectra of the NiCe NPs and $\mathrm{Ni} / \mathrm{CeO}_{2}$ after $\mathrm{H}_{2}$ and $\mathrm{O}_{2}$ treatments at two characteristic temperatures are shown in Fig. 4. Comparison of the relative $\mathrm{Ni} 2 \mathrm{p}$ to $\mathrm{Ce} 3 \mathrm{~d}$ peak intensities between the two samples shows that in case of $\mathrm{Ni} / \mathrm{CeO}_{2}$ the intensity of $\mathrm{Ni} 2 \mathrm{p}$ peak is enhanced as compared to the NiCe NPs. In particular, the atomic ratio of $\mathrm{Ni}$ from about $12 \pm 2$ at $\mathrm{Ni}_{0.1} \mathrm{Ce}_{0.9} \mathrm{O}_{2-x}$ increases to $35 \pm 2$ in case $\mathrm{Ni} / \mathrm{CeO}_{2}$, which seems surprising since both samples have the same nominal Ni loading. This is rationalized by taking into account the differences in the morphology of the two samples. The co-precipitation forms Ni particles dispersed on the ceria surface, ${ }^{31}$ while $\mathrm{Ni}$ in the case of NiCe NPs is inserted into ceria lattice. Given that XPS is surface sensitive, Ni particles dispersed over ceria support $\left(\mathrm{Ni} / \mathrm{CeO}_{2}\right)$ is expected to have an enhanced Ni atomic ratio in XPS, as compared to Ni atoms inserted into the fluorite lattice of ceria (NiCe NPs).

Apart of the differences in the peak area ratio, the two samples exhibit clear differences also in the peak shape (Fig. 5). As discussed above, in $\mathrm{O}_{2}$ and low temperature $\mathrm{H}_{2}$ the $\mathrm{Ni} 2 \mathrm{p}_{3 / 2}$ peak of NiCe NPs is likely due to $\mathrm{Ni}^{3+}$ species. In case of $\mathrm{Ni} / \mathrm{CeO}_{2}$ the main $\mathrm{Ni} 2 \mathrm{p}_{3 / 2}$ peak at $854.1 \mathrm{eV}$ is accompanied by a prominent shoulder around $855.3 \mathrm{eV}$ and an intense satellite feature

Table 1 Cell parameters of the $\mathrm{Ni}_{0.1} \mathrm{Ce}_{0.9} \mathrm{O}_{2-x} \mathrm{NPs}$ and $10 \% \mathrm{Ni} / \mathrm{CeO}_{2}$ as defined by in situ $\mathrm{XRD}$, after $\mathrm{O}_{2}$ and $\mathrm{H}_{2}$ annealing at $400{ }^{\circ} \mathrm{C}$

\begin{tabular}{lll}
\hline & $\begin{array}{l}a_{\text {Ceria }}(\AA) \\
\text { at } 25{ }^{\circ} \mathrm{C} \text {, after annealing at } 400{ }^{\circ} \mathrm{C} \text {, under } 96 \% \\
\mathrm{~N}_{2}-4 \% \mathrm{O}_{2}\end{array}$ & $\begin{array}{l}a_{\text {Ceria }}(\AA) \\
\text { at } 25{ }^{\circ} \mathrm{C} \text {, after annealing at } 400{ }^{\circ} \mathrm{C}, \text { under } 96 \% \\
\mathrm{~N}_{2}-4 \% \mathrm{H}_{2}\end{array}$ \\
\hline $\mathrm{Cample}$ & $5.4103(1)$ & $5.4109(1)$ \\
$\mathrm{CeO}_{2} / \mathrm{NiO}(10 \mathrm{~mol} \%)$ & $5.421(1)$ & $5.424(1)$
\end{tabular}




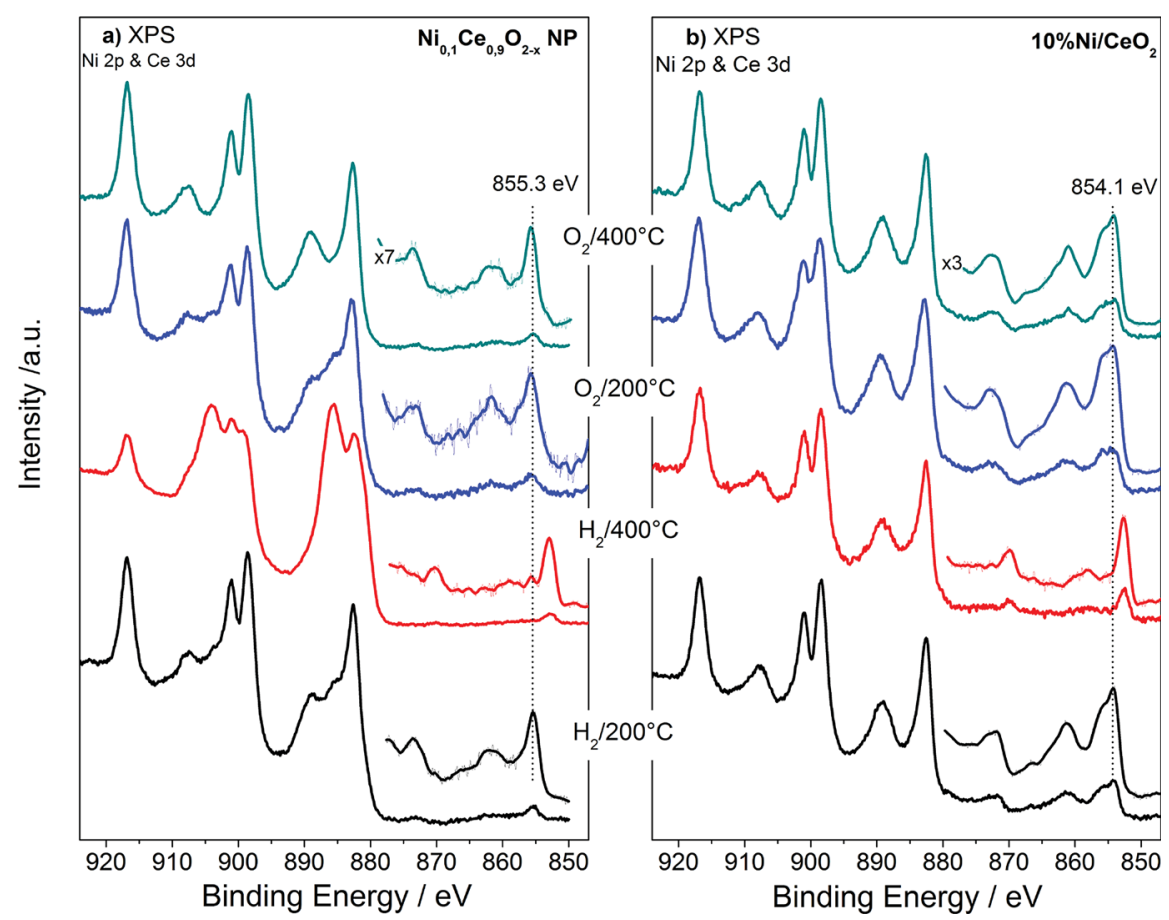

Fig. $4 \mathrm{Ni} 2 \mathrm{p}$ and $\mathrm{Ce} 3 \mathrm{~d}$ XPS spectra of $\mathrm{Ni}_{0.1} \mathrm{Ce}_{0.9} \mathrm{O}_{2-x} \mathrm{NPs}$ (a) and $10 \% \mathrm{Ni} / \mathrm{CeO}_{2}$ (b) upon treatment up to $400{ }^{\circ} \mathrm{C}$ in $\mathrm{O}_{2}$ and $\mathrm{H}_{2}$ atmospheres.

(50 $\pm 5 \%$ of the main $\mathrm{Ni} 2 \mathrm{p}_{3 / 2}$ peak height) shifted $6.9 \mathrm{eV}$ of the main peak (Fig. 5a), typical characteristics of the Ni 2p spectrum for bulk NiO. ${ }^{22-25}$ These differences confirms that in the case of NiCe NPs nickel is mainly in the $\mathrm{Ni}^{3+}$ state, while for $\mathrm{Ni} / \mathrm{CeO}_{2}$ is oxidized to $\mathrm{NiO}\left(\mathrm{Ni}^{2+}\right.$ valence) and reveals a fundamental chemical modification of nickel impended in the ceria lattice as compared to supported nickel particles. The oxidation state of nickel remains unchanged up to $200{ }^{\circ} \mathrm{C}$ in $\mathrm{H}_{2}$, while at $400{ }^{\circ} \mathrm{C}$ in $\mathrm{H}_{2} \mathrm{Ni} 2 \mathrm{p}_{3 / 2}$ shifts at $852.7 \mathrm{eV}$ and the satellite peak intensity drops considerably. This is a clear indication of reduction of nickel to the metallic state for both samples and completes the XRD observations shown above.

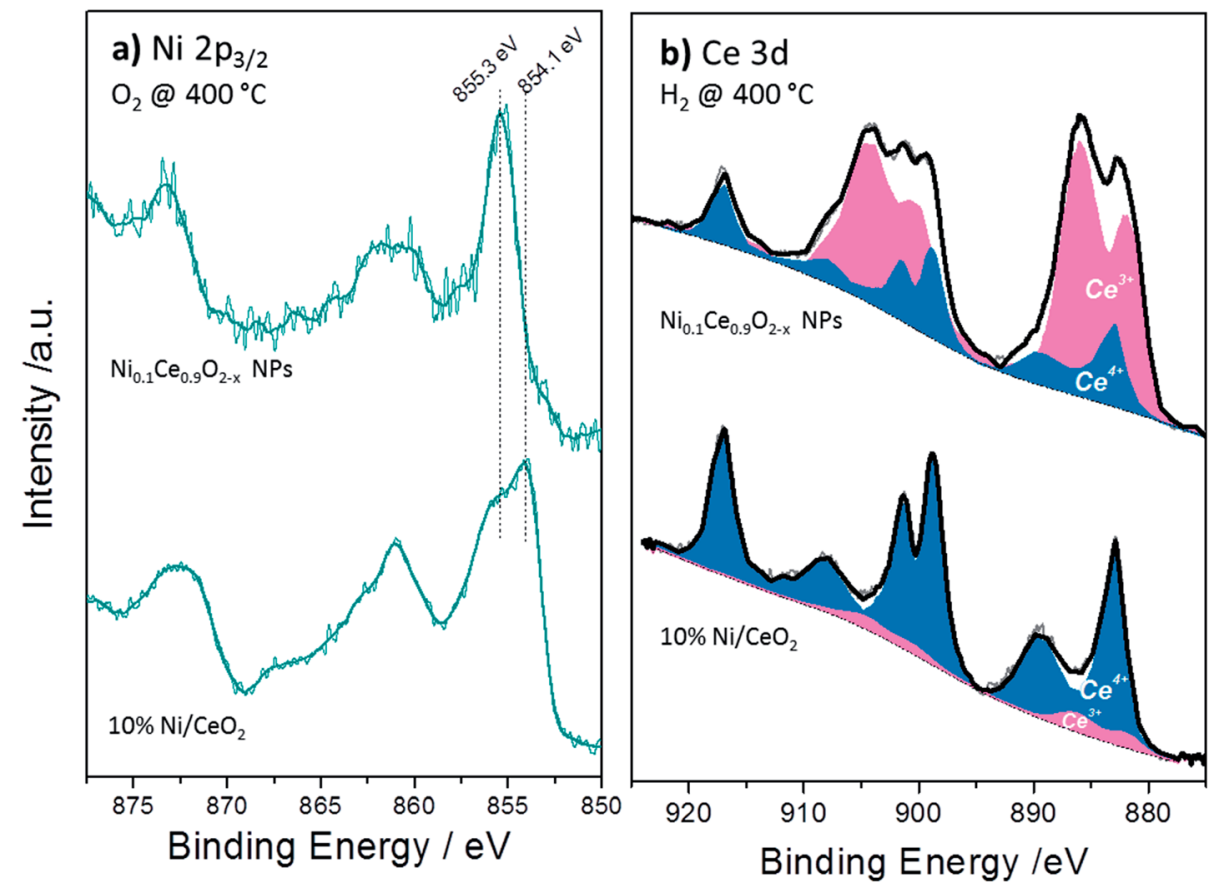

Fig. 5 (a) Comparison of the $\mathrm{Ni} 2 \mathrm{p}_{3 / 2}$ spectra between $10 \% \mathrm{Ni} / \mathrm{CeO}_{2}$ and $\mathrm{NiCe} \mathrm{NPs}$ samples recorded after calcination at $400{ }^{\circ} \mathrm{C}$ (b) deconvolution procedure of two characteristic $\mathrm{Ce} 3 \mathrm{~d}$ XPS spectra using $\mathrm{Ce}^{4+}$ and $\mathrm{Ce}^{3+}$ line shapes derived from reference samples recorded under identical reduction conditions $\left(400{ }^{\circ} \mathrm{C}\right.$ in $\left.\mathrm{H}_{2}\right)$. 
Table 2 The \% concentration of $\mathrm{Ce}^{3+}$ species at different gas treatments as derived by the analysis of the Ce $3 d$ XPS spectra

\section{$\% \mathrm{Ce}^{3+}$}

\begin{tabular}{lcc} 
Conditions & $\mathrm{Ni}_{0.1} \mathrm{Ce}_{0.9} \mathrm{O}_{2-x}$ & $10 \% \mathrm{Ni} / \mathrm{CeO}_{2}$ \\
\hline Calcined & 0 & 0 \\
$200^{\circ} \mathrm{C}$ in $\mathrm{H}_{2}$ & 27 & 5 \\
$400^{\circ} \mathrm{C}$ in $\mathrm{H}_{2}$ & 74 & 10 \\
$200^{\circ} \mathrm{C}$ in $\mathrm{O}_{2}$ & 31 & 10 \\
$400{ }^{\circ} \mathrm{C}$ in $\mathrm{O}_{2}$ & 0 & 0
\end{tabular}

The Ce $3 \mathrm{~d}$ spectra of the two samples differ considerably after $\mathrm{H}_{2}$ and $\mathrm{O}_{2}$ treatments. The $\% \mathrm{Ce}^{3+}$ species obtained after deconvolution of Ce $3 \mathrm{~d}$ peak in $\mathrm{Ce}^{3+}$ and $\mathrm{Ce}^{4+}$ components (Fig. 5b) are given in Table 2. From this table it is clear that under identical $\mathrm{H}_{2}$ treatment conditions the amount of $\mathrm{Ce}^{3+}$ species for NiCe NPs is up to 7 times higher as compared to Ni/ $\mathrm{CeO}_{2}$. The ceria stoichiometry in case of NiCe NPs, as calculated by the $\% \mathrm{Ce}^{3+}$ at $400{ }^{\circ} \mathrm{C}$ in $\mathrm{H}_{2}$, is $\mathrm{CeO}_{1.63}$. Such a composition adopts a Bixbyite type $\mathrm{C}-\mathrm{Ce}_{2} \mathrm{O}_{3+\delta}$ structure, ${ }^{32}$ which has a cubic superstructure ( $a \approx 11.11 \AA$ ), originating from the ordering of oxygen vacancies along the [111] direction of the fluorite type structure. The calculated XRD pattern of $\mathrm{C}-\mathrm{Ce}_{2} \mathrm{O}_{3+\delta}$ contains several superstructure peaks of low intensity at $2 \theta 19.5^{\circ}, 34.2^{\circ}$, $37.9^{\circ}$ and $41.4^{\circ}$, in addition to intense peaks at $2 \theta 27.8^{\circ}, 32.2^{\circ}$, $46.2^{\circ}$ similar to those observed for $\mathrm{CeO}_{2}$. However the detection of the small superstructure peaks characteristic of the $\mathrm{C}$ $\mathrm{Ce}_{2} \mathrm{O}_{3+\delta}$ phase in the XRD pattern of NiCe NPs (Fig. S3 $\dagger$ ), is impossible due to a broadening of all Bragg peaks induced by the small size of coherent diffraction domains (37(4) $\mathrm{A})$.

Doped-ceria nanoparticles have been studied for a number of applications including catalytic CO oxidation ${ }^{\mathbf{1 0 , 1 1}}$ and electrocatalytic $\mathrm{CO}_{2}$ reduction, ${ }^{33}$ showing an excellent performance as compared to standard supported catalysts. The reducibility of ceria, i.e. the facile transformation of Ce cations from $\mathrm{Ce}^{4+}$ to $\mathrm{Ce}^{3+}$, is a crucial property for the catalytic applications since it is related to the ability of the material to release and uptake $O$ atoms during reactions. ${ }^{34}$ The present findings show that the reducibility of ceria is enhanced when $\mathrm{Ni}$ is doped into the lattice, as compared to Ni deposited over ceria supports. The enhanced reducibility of NiCe NPs can be used to design improved catalysts when enhanced ceria reducibility is required. For example, facile ceria reduction is known to promote heterogeneous catalytic reactions following the Marsvan-Krevelen reaction mechanism..$^{35,36}$

Apart of the apparent influence on the ceria reducibility, the synthetic strategy reported here has an additional advantage which is related to the fact that the NiCe NPs are solved in hexane solution. This solvent has a high viscosity $(0.30 \mathrm{mPa}$ s@25 ${ }^{\circ} \mathrm{C}$ ) which allows facile access of the solution containing NiCe NPs via capillary forces into the channels of porous supports as compared to NPs in aqueous media. High viscosity can find direct application for the use of this material in the preparation of solid oxide cell electrodes (SOCE). In recent years there is an increase interest to fabricate SOCE by direct infiltration of the electrode material on a porous electrolyte scaffold. ${ }^{37-40}$ Typically, ceria is deposited from nitrate solutions which have much lower viscosity than hexane, often resulting in a non-uniform in depth distribution of ceria into the pores of the scaffold. The application of doped ceria nanoparticles prepared by the method described in this work for the development of highly efficient SOCE, will be explored in future studies. We expect that the enhanced reducibility of ceria which was evident in this study, in combination with the facile application of the nanoparticles into the channels of the scaffold, based on the high viscosity of hexane solutions, is a promising combination which can contribute to the development of more robust and active solid oxide electrodes for fuel cell and electrolysis applications.

\section{Conclusions}

In summary, $\mathrm{Ni}_{0.1} \mathrm{Ce}_{0.9} \mathrm{O}_{2-x}$ nanoparticles with mean diameter of about $4 \mathrm{~nm}$, were synthesized from heterobimetallic Schiff base complexes precursors using a two-step process. The as prepared particles are dispersed in hexane solution and later dropped casted onto planar supports for characterization. A variety of analytical methods including, XPS, XRD, Raman, STEM, and SEM were applied to ascertain the structure, morphology and chemical state of the nanoparticles before and after calcination at $400{ }^{\circ} \mathrm{C}$. Among other things, the results illustrated the presence of trivalent $\mathrm{Ni}^{3+}$ ions and a considerably high amount of defect sites into the ceria particles. The reduction/oxidation of the $\mathrm{Ni}_{0.1} \mathrm{Ce}_{0.9} \mathrm{O}_{2-x}$ nanoparticles in $\mathrm{H}_{2}$ / $\mathrm{O}_{2}$ ambients respectively, was studied by XPS and in situ XRD. For comparison ceria-supported nickel particles prepared by standard co-precipitation method, were examined under the same conditions. Notably, the surface reducibility of ceria is enhanced when $\mathrm{Ni}$ is doped into the ceria lattice, as compared to ceria acting just as the $\mathrm{Ni}$ support. Considering that the reducibility of ceria determines to a large extent the facility of this material to store and release oxygen, the $\mathrm{Ni}_{0.1} \mathrm{Ce}_{0.9} \mathrm{O}_{2-x}$ nanoparticles prepared by this method can be potentially exploited in a variety of technological fields such as heterogeneous catalysis and solid oxide electrochemical cells.

\section{Conflicts of interest}

There are no conflicts to declare.

\section{Acknowledgements}

S. Z., F. P. and B. M. acknowledge financial support from the Fuel Cells and Hydrogen 2 (H2020) Joint Undertaking under Project SElySOs with Grant Agreement 671481. We thank Dr T. Dintzer for the SEM images and Prof. A. Ourari for his suggestions regarding the synthesis.

\section{References}

1 T. Montini, M. Melchionna, M. Monai and P. Fornasiero, Chem. Rev., 2016, 116, 5987-6041. 
2 J. Wang, H. Chen, Z. Hu, M. Yao and Y. Li, Catal. Rev.: Sci. Eng., 2015, 57, 79-144.

3 X. Liu, K. Zhou, L. Wang, B. Wang and Y. Li, J. Am. Chem. Soc., 2009, 131, 3140-3141.

4 Y. Ma, W. Gao, Z. Zhang, S. Zhang, Z. Tian, Y. Liu, J. C. Ho and Y. Qu, Surf. Sci. Rep., 2018, 73, 1-36.

5 A. Trovarelli and J. Llorca, ACS Catal., 2017, 7, 4716-4735.

6 X.-F. Yang, A. Wang, B. Qiao, J. Li, J. Liu and T. Zhang, Acc. Chem. Res., 2013, 46, 1740-1748.

7 M. Flytzani-Stephanopoulos and B. C. Gates, Annu. Rev. Chem. Biomol. Eng., 2012, 3, 545-574.

8 S. Mahammadunnisa, P. Manoj Kumar Reddy, N. Lingaiah and C. Subrahmanyam, Catal. Sci. Technol., 2013, 3, 730-736.

9 W. L. Wang, W. Y. Liu, X. L. Weng, Y. Shang, J. J. Chen, Z. G. Chen and Z. B. Wu, J. Mater. Chem. A, 2018, 6, 866-870.

10 C. D. Curran, L. Lu, C. J. Kiely and S. McIntosh, J. Mater. Chem. A, 2018, 6, 244-255.

11 J. S. Elias, M. Risch, L. Giordano, A. N. Mansour and Y. ShaoHorn, J. Am. Chem. Soc., 2014, 136, 17193-17200.

12 J. Rodríguez-Carvajal, Phys. B, 1993, 192, 55-69.

13 Z. Weng, W. Liu, L. C. Yin, R. Fang, M. Li, E. I. Altman, Q. Fan, F. Li, H. M. Cheng and H. Wang, Nano Lett., 2015, 15, 7704-7710.

14 G. Zhou, L. Barrio, S. Agnoli, S. D. Senanayake, J. Evans, A. Kubacka, M. Estrella, J. C. Hanson, A. Martínez-Arias, M. Fernández-García and J. A. Rodriguez, Angew. Chem., Int. Ed., 2010, 49, 9680-9684.

15 R. D. Shannon, Acta Crystallogr., Sect. A: Cryst. Phys., Diffr., Theor. Gen. Crystallogr., 1976, 32, 751-767.

16 T. Taniguchi, T. Watanabe, N. Sugiyama, A. K. Subramani, H. Wagata, N. Matsushita and M. Yoshimura, J. Phys. Chem. C, 2009, 113, 19789-19793.

17 B. Xu, Q. Zhang, S. Yuan, M. Zhang and T. Ohno, Appl. Catal., $B, 2016,183,361-370$.

18 C. A. Chagas, E. F. de Souza, R. L. Manfro, S. M. Landi, M. M. V. M. Souza and M. Schmal, Appl. Catal., B, 2016, 182, 257-265.

19 M. Li, U. Tumuluri, Z. Wu and S. Dai, ChemSusChem, 2015, 8, 3651-3660.

20 B. Paul, K. Kumar, A. Chowdhury and A. Roy, J. Appl. Phys., 2017, 122, 135108.

21 V. Papaefthimiou, M. Shishkin, D. K. Niakolas, M. Athanasiou, Y. T. Law, R. Arrigo, D. Teschner, M. Hävecker, A. Knop-Gericke, R. Schlögl, T. Ziegler, S. G. Neophytides and S. Zafeiratos, Adv. Energy Mater., 2013, 3, 762-769.
22 V. V. Kaichev, D. Teschner, A. A. Saraev, S. S. Kosolobov, A. Y. Gladky, I. P. Prosvirin, N. A. Rudina, A. B. Ayupov, R. Blume, M. Hävecker, A. Knop-Gericke, R. Schlögl, A. V. Latyshev and V. I. Bukhtiyarov, J. Catal., 2016, 334, 23-33.

23 B. P. Payne, M. C. Biesinger and N. S. McIntyre, J. Electron Spectrosc. Relat. Phenom., 2009, 175, 55-65.

24 M. C. Biesinger, L. W. M. Lau, A. R. Gerson and R. S. C. Smart, Phys. Chem. Chem. Phys., 2012, 14, 2434.

25 M. C. Biesinger, B. P. Payne, L. W. M. Lau, A. Gerson and R. S. C. Smart, Surf. Interface Anal., 2009, 41, 324-332.

26 A. F. Carley, S. D. Jackson, J. N. O'Shea and M. W. Roberts, Surf. Sci., 1999, 440, L868-L874.

27 A. F. Carley, S. D. Jackson, J. N. O'Shea and M. W. Roberts, Phys. Chem. Chem. Phys., 2001, 3, 274-281.

28 H. Sohn, I. I. Soykal, S. Zhang, J. Shan, F. Tao, J. T. Miller and U. S. Ozkan, J. Phys. Chem. C, 2016, 120, 14631-14642.

29 W. Luo, W. Baaziz, Q. Cao, H. Ba, R. Baati, O. Ersen, C. Pham-Huu and S. Zafeiratos, ACS Appl. Mater. Interfaces, 2017, 9(39), 34256-34268.

30 W. Qi, K. Xie, M. Liu, G. Wu, Y. Wang, Y. Zhang and Y. Wu, RSC Adv., 2014, 4, 40494-40504.

31 B. Nematollahi, M. Rezaei and E. N. Lay, Int. J. Hydrogen Energy, 2015, 40, 8539-8547.

32 E. Kümmerle and G. Heger, J. Solid State Chem., 1999, 147, 485-500.

33 Y. Wang, Z. Chen, P. Han, Y. Du, Z. Gu, X. Xu and G. Zheng, ACS Catal., 2018, 8, 7113-7119.

34 W. Zou, C. Ge, M. Lu, S. Wu, Y. Wang, J. Sun, Y. Pu, C. Tang, F. Gao and L. Dong, RSC Adv., 2015, 5, 98335-98343.

35 M. Lykaki, E. Pachatouridou, S. A. C. Carabineiro, E. Iliopoulou, C. Andriopoulou, N. Kallithrakas-Kontos, S. Boghosian and M. Konsolakis, Appl. Catal., B, 2018, 230, 18-28.

36 I. Y. Kaplin, E. S. Lokteva, E. V. Golubina, K. I. Maslakov, N. E. Strokova, S. A. Chernyak and V. V. Lunin, RSC Adv., 2017, 7, 51359-51372.

37 J. M. Vohs and R. J. Gorte, Adv. Mater., 2009, 21, 943-956.

38 P. Boldrin, E. Ruiz-Trejo, J. W. Yu, R. I. Gruar, C. J. Tighe, K. C. Chang, J. Ilavsky, J. A. Darr and N. Brandon, J. Mater. Chem. A, 2015, 3, 3011-3018.

39 A. Chrzan, S. Ovtar, P. Jasinski, M. Chen and A. Hauch, J. Power Sources, 2017, 353, 67-76.

40 X. Lou, Z. Liu, S. Wang, Y. Xiu, C. P. Wong and M. Liu, J. Power Sources, 2010, 195, 419-424. 